\title{
Influência de fatores socioeconômicos e nutricionais no consumo de proteína animal em Itapecuru Mirim, Maranhão
}

Objetivou-se, com o presente trabalho, avaliar a preferência do consumidor em relação à proteína animal em Itapecuru Mirim, Maranhão, Brasil. Para a obtenção dos dados, foram aplicados 100 questionários semiestruturados, constituídos por 18 questões que abordavam aspectos relativos às condições de consumo e preferência por diferentes tipos de carnes no município. Os dados foram submetidos à análise estatística descritiva, com ênfase na distribuição de frequências relativas das respostas. Observou-se que os consumidores apresentam maior preferência por carne de frango (62\%), seguidos pelos que preferem carne bovina (30\%), e a suína sendo a menos consumida ( $8 \%$ ). Sendo que o principal motivo da carne de frango ser a mais consumida o costume (30\%), seguindo pelo valor nutritivo (25\%), pelo preço acessivel (24\%), e os demais por outros fatores (4\%). Além disso, observou-se que os consumidores que relacionam a produção animal com danos ao meio ambiente são a maioria (36\%), seguindo dos entrevistados que não souberam responder (24\%), aqueles que responderam que prejudica $(22 \%)$ e que não prejudica $(18 \%)$. Os resultados mostraram que o consumo de carne suína e bovina se mostrou limitado na cidade, sendo importante o emprego de estratégias que desmistificação sobre suas qualidades e demais características.

Palavras-chave: Atributos de qualidade; Comércio de carnes; Pesquisa de consumo; Segurança alimentar.

\section{Influence of socioeconomic and nutritional factors on animal protein consumption in Itapecuru Mirim, Maranhão}

\begin{abstract}
The objective of this study was to evaluate consumer preference in relation to animal protein in Itapecuru Mirim, Maranhão, Brazil. To obtain the data, 100 semistructured questionnaires were applied, consisting of 18 questions that addressed aspects related to the conditions of consumption and preference for different types of meat in the municipality. The data were submitted to descriptive statistical analysis, with emphasis on the distribution of the relative frequencies of the responses. It was observed that consumers have a greater preference for chicken meat (62\%), followed by those who prefer beef ( $30 \%)$, and pork being the least consumed ( $8 \%)$. The main reason for chicken meat being the most consumed is the custom ( $30 \%)$, followed by the nutritional value ( $25 \%)$, the affordable price $(24 \%)$, and the rest by other factors (4\%). In addition, it was observed that consumers who relate animal production to damage to the environment are the majority (36\%), followed by respondents who did not know how to respond (24\%), those who responded that it harms (22\%) and that does not harm (18\%). The results showed that the consumption of pork and beef was limited in the city, being important the use of strategies that demystify its qualities and other characteristics.
\end{abstract}

Keywords: Quality attributes; Meat trade; Consumer research; Food security.

Reviewed anonymously in the process of blind peer.

Ricardo Alves de Araújo (D)

Universidade Estadual do Maranhão, Brasi

http://orcid.org/0000-0001-9696-5680

ricardo zoo@hotmail.com

Olivan Cunha Almeida

Universidade Federal do Maranhão, Brasil http://lattes.cnpq.br/2467527138241747

olivan.almeida.tec@gmail.com

Luiza de Nazaré Carneiro da Carneiroda Silva luiza.zootecnia@gmail.com

\section{Silvan Ferreira Morais}

Universidade Federal do Maranhão, Brasil http://lattes.cnpq.br/4843224105308556 silvandymoraes@gmail.com
Edmilson Igor Bernardo Almeida (D) Universidade Federal do Maranhão, Brasil http://lattes.cnpq.br/4485991332506597 http://orcid.org/0000-0003-2051-7085 edmilson i@hotmail.com

\section{Rosana Maria Vale de Almeida}

Universidade Estadual do Maranha, Brasil http://lattes.cnpq.br/8526708535857302 almeidarosana794@gmail.com

Diego de Almeida Veras

Universidade Federal do Maranhão, Brasil http://lattes.cnpq.br/3472321177348257 verasdiego27@gmail.com

\section{Rodrigo Alves de Sousa}

Universidade Federal do Maranhão, Brasil http://lattes.cnpq.br/7214535426870055 rodrigoaszootecnia@gmail.com
Renato Sousa Corrêa

Universidade Federal do Maranhão, Brasil http://lattes.cnpq.br/9614469946735320 sousa.renato@discente.ufma

Enilton Silva Rodrigues

Universidade Federal do Maranhão, Brasil http://lattes.cnpq.br/4647791797730920 enilton50@gmail.com

Maurivan Barbosa Pacheco

Universidade Federal do Maranhão, Brasil http://lattes.cnpq.br/2593810903242525 maurivanpacheco@gmail.com

Vanessa Brito Barroso

Universidade Federal do Maranhão, Brasil http://lattes.cnpq.br/6848925247182712 vanessaflicka@hotmail.com

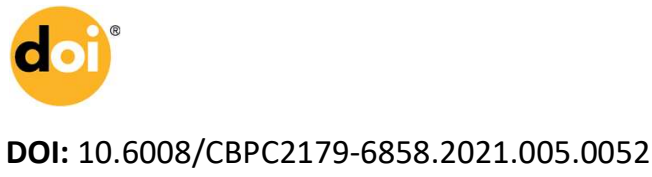

DOI: 10.6008/CBPC2179-6858.2021.005.0052
Referencing this:

ARAÚJO, R. A.; ALMEIDA, O. C.; SILVA, L. N. C. C.; MORAIS, S. F.; ALMEIDA, E. I. B.; ALMEIDA, R. M. V.; VERAS, D. A.; SOUSA, R. A.; CORRÊA, R. S.; RODRIGUES, E. S.; PACHECO, M. B.; BARROSO, V. B. Influência de fatores socioeconômicos e nutricionais no consumo de proteína animal em Itapecuru Mirim, Maranhão. Revista Ibero Americana de Ciências Ambientais, v.12, n.5, p.671-680, 2021. DOI: http://doi.org/10.6008/CBPC2179-6858.2021.005.0052 


\section{INTRODUÇÃO}

Em geral, apesar de muito combatido, o consumo de proteína animal deve ser diário. No entanto, a recomendação de consumo de carne vermelha na literatura é muito variada. Para uma dieta de 2.200 calorias/dia, por exemplo, a recomendação do Dietary Guidelines for Americans (2010) para o consumo de alimentos proteicos é de 171,1 g/dia, sendo que a ingestão de carnes vermelhas (bovinos, ovinos e suínos) não deve ultrapassar o limite de 56 g/dia. Já o Food Guide Pyramid Recommendations (1992) recomenda somente um consumo de produtos proteicos entre 155,5 a $217,7 \mathrm{~g} / \mathrm{dia}$, sem diferenciar a origem do alimento.

Independentemente das controvérsias acerca do consumo de proteínas de origem animal, o que é comprovado cientificamente são os benefícios ao organismo humano, haja vista que os nutrientes da carne desempenham inúmeras funções destinadas, tais como enzimas, hormônios, proteínas transportadoras, anticorpos e receptores de muitas células. Neste contexto, a produção de carnes está crescendo a taxas maiores em decorrência do aumento da produtividade. Por outro lado, a escolha do consumidor no mercado é muito condicionada à oferta de diferentes tipos de carne. Nas últimas décadas, não só o consumo de alimentos vem apresentando fortes transformações, os consumidores também estão mais exigentes e preocupados com a segurança alimentar. Sendo que em sua grande maioria a escolha por cada tipo de carne é diretamente influenciada pela renda da população, pelo preço e pelo acesso ser mais simples (RECK et al., 2016). Dessa forma, a determinação das reações dos consumidores em larga escala pode fornecer evidências para melhor atender o mercado, o principal desafio da indústria de carne é se tornar mais orientada ao consumidor, o que contribui para justificar a importância do estabelecimento das demandas dos consumidores por esse produto (FIGUEIREDO JÚNIOR et al., 2017).

Embora muitas das vezes o consumidor avalie apenas os aspectos da qualidade visual da carne crua, como a cor do músculo e da gordura, sendo que é necessário analisar a importância do produto quanto ao fornecimento de nutrientes que são indispensáveis para o ser humano obter desempenho positivo no organismo. Desta forma, objetiva-se com este trabalho analisar a preferência do consumidor em relação à proteína animal em Itapecuru Mirim.

\section{METODOLOGIA}

A presente pesquisa foi realizada no município de Itapecuru Mirim MA, localizado na região Nordeste do Brasil a 117,3 km de São Luís capital Maranhense. Sua população foi estimada pelo IBGE em aproximadamente 67.104 habitantes. Tendo um clima tropical úmido, onde a época mais chuvosa é o verão, temperatura média anual de 27,30 ㄷ, com pluviosidade média anual de $1.632 \mathrm{~mm}$ e PIB per capita de R\$ 7.276.00 (IBGE, 2017). Para o desenvolvimento da pesquisa foram entrevistadas 100 pessoas com o propósito de analisar o consumo de proteína animal na cidade de Itapecuru- Mirim, Maranhão. A presente pesquisa foi de natureza descritiva, estruturada como um levantamento do tipo survey, com base em corte transversal, com variáveis qualitativas e quantitativas (MARCONI et al., 2007).

Quanto aos dados e informações, serão coletadas através de questionário, de forma aleatória em 
alguns bairros do município. A caracterização da amostra como intencional dar-se-á pela opção em não abordar indivíduos que estejam conversando, efetuando alguma compra, acompanhados por mais de uma pessoa, deslocando-se com rapidez ou carregando sacolas ou objetos pesados e/ou volumosos. Todo entrevistado deverá ter idade igual ou superior a 18 anos e não ser turista. A análise dos dados foi feita por estatística descritiva e apresentados em gráficos e tabelas, conforme o tipo de variável analisada.

\section{RESULTADOS E DISCUSSÃO}

Observou-se que em Itapecuru Mirim, os consumidores entrevistados apresentam maior preferência por carne de frango (62\%), seguidos pelos que preferem carne bovina (30\%), e a suína sendo a menos consumidas (8\%), conforme se pode observar na Figura 1. Os dados observados no município são coerentes e corroboram com a tendência nacional, haja vista que, no Brasil, a carne mais consumida é a de frango, com 45,9 quilos por habitante ao ano (FAO, 2019). Ressalta-se também que o consumo de carne de frango vem crescendo como alternativa mais barata para substituir a carne bovina nas faixas de renda mais baixa, principalmente, nas regiões em desenvolvimento (AGUIAIS et al., 2015), como é o caso do estado do Maranhão, o qual possui um médio IDH $(0,639)$, sendo o de Itapecuru-Mirim baixo $(0,599)$, o que afirma ainda mais essa hipótese.

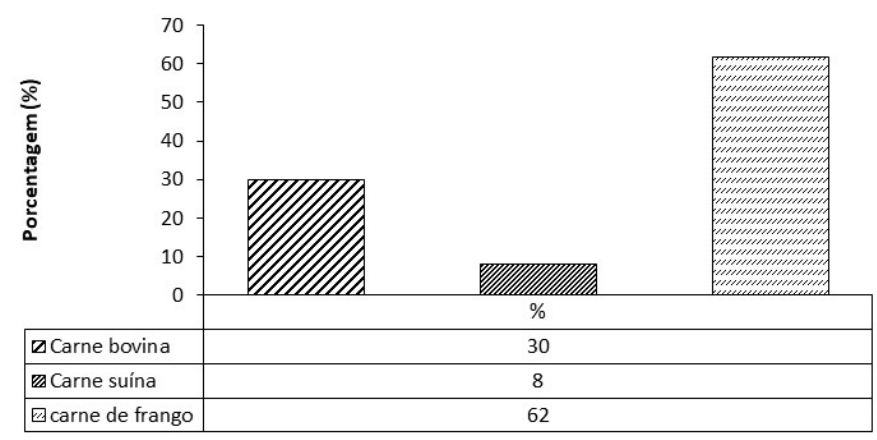

Figura 1: Preferência dos consumidores em Itapecuru Mirim pelo tipo de proteína animal

Quando se analisou qual o motivo pela preferência do consumo da carne bovina em Itapecuru Mirim, observou-se que o maior motivo é a preferência pelo sabor (56\%), seguindo pelos que relataram os costumes (38\%), e os demais pelo fato do valor nutritivo (6\%), sendo que nenhum dos entrevistados levam em consideração o preço da carne bovina (0\%), conforme observa-se na Figura 2. Segundo Velho et al. (2009), o atributo que mais determina a compra de carne bovina pelos consumidores é a cor, seguida pela maciez e pelo preço da carne. Segundo Lima Júnior et al. (2011) a cor da carne influencia na aquisição do produto nas gôndolas dos mercados e é o principal parâmetro utilizado no julgamento de compra do consumidor. A maciez da carne bovina está associada à qualidade global do produto e que fideliza o consumidor. Desta forma, pode-se inferir que os consumidores de carne bovina em Itapecuru Mirim correlacionam a aparência da carne bovina com a qualidade e, consequentemente, com o sabor. É interessante destacar também que segundo Verbeke et al. (2010) os consumidores acreditam que carne bovina não deve ser consumida diariamente, eles reconheceram o seu valor nutricional e sua contribuição para uma dieta saudável. 


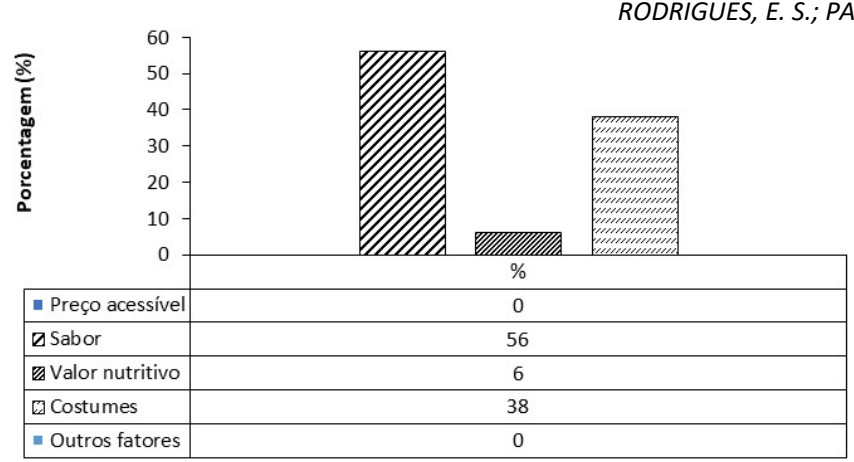

Figura 2: Motivo da preferência dos consumidores em Itapecuru Mirim pela carne bovina

Verificou-se que o motivo da preferência dos consumidores de carne suína em Itapecuru Mirim, tendo como maior opção o sabor (50\%), seguindo pelos costumes $(25 \%)$, com valor nutritivo $(12,5 \%)$ e os que preferem por outros fatores $(12,5 \%)$, onde os consumidores da carne suína não levam em consideração o preço acessível (0\%) da proteína (Figura 3). Deve-se ressaltar que a carne suína é a mais produzida e consumida no mundo. O Brasil, quarto maior produtor desse alimento, ficando atrás apenas da China, União Europeia e Estados Unidos, atingiu uma produção de 3,759 milhões de toneladas no ano de 2018 (ABPA, 2019).

Dados de pesquisa com consumidores que mostram a carne suína como menos apreciada que a carne bovina e a de frango também foram obtidos por Faria et al. (2006), em estudo realizado na cidade de Belo Horizonte, MG, que observaram preferência de 35,4\% dos consumidores pela carne de frango, 35,4\% pela carne bovina e apenas $26,7 \%$ pela carne suína. Segundo Santos Filho et al. (2007), o consumo de carne suína não é homogêneo em todo o Brasil, sendo os Estados do Norte os que menos consomem e os Estados do Sul os maiores consumidores.

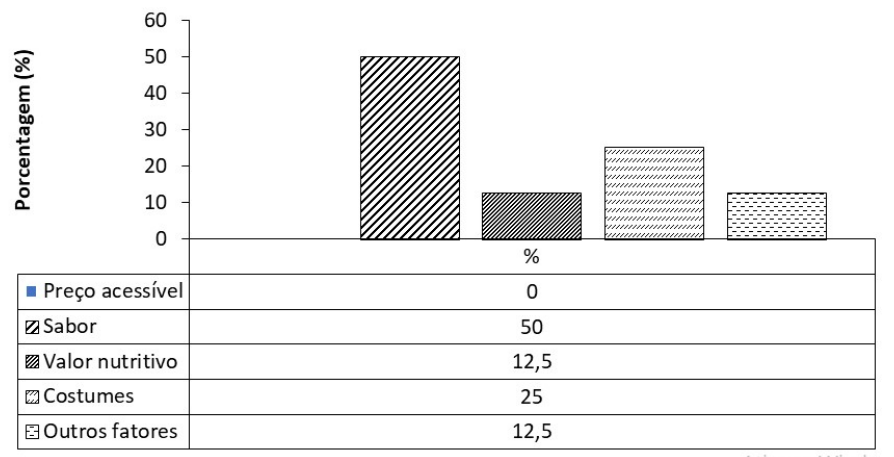

Figura 3: Motivo da preferência dos consumidores em Itapecuru Mirim pela carne suína

Observou-se que, para o consumo de carne de frango, os consumidores apontaram como maior preferência o costume (30\%), seguindo pelo valor nutritivo (25\%), outros pelo preço acessível (24\%), e os demais por outros fatores (4\%), conforme se observa na figura 4. No contexto brasileiro, Gordin (2002) afirma que entre os fatores que mais contribuíram para o aumento do consumo de carne de frango estão o aumento na eficiência de toda a cadeia produtiva, com a subsequente redução de preços, alterações no poder aquisitivo da população e o baixo custo em relação aos seus substitutos. Desta forma, há certa correlação do contexto nacional com o local, haja vista que no município de Itapecuru Mirim a cadeia produtiva de frangos já está bem estruturada, contribuindo assim com o costume no consumo de carne de 
frangos.

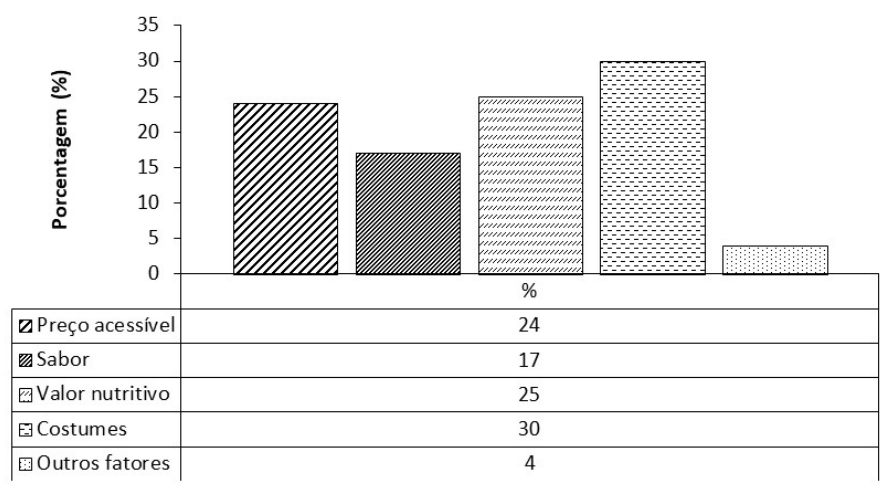

Figura 4: Motivo da preferência dos consumidores em Itapecuru Mirim pela carne de frango

Observou-se a preferência dos consumidores pelo modo de preparo da carne bovina, onde teve como maior preferência todas as formas de preparo (47\%), cozida (33\%), assada (10\%) e frita (10\%), conforme se pode observar na figura 5. Esses dados são bem interessantes, haja vista que mostram uma grande versatilidade dos consumidores acerca das diferentes formas de preparo da carne bovina.

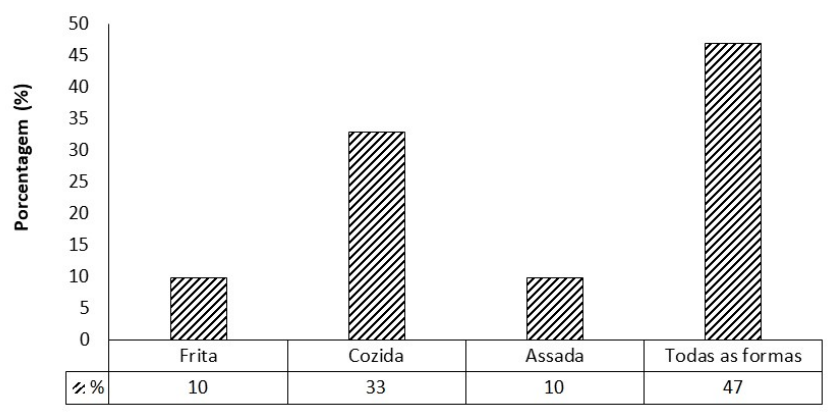

Figura 5: Preferência dos consumidores em Itapecuru Mirim pelo modo de preparo da carne bovina.

Verificou-se quanto ao modo de preparo da carne suína, onde teve como maior preferência todas as formas de preparo (50\%), assada (25\%), cozida (12,5\%) e frita $(12,5 \%)$, conforme se observa na Figura 6. Assim como a carne bovina, os consumidores de carne suína apresentam grande versatilidade na sua forma de preparo. O modo de preparar essa carne é uma questão de rotina, cultura, hábito e de consumo, alegando eles que torna o sabor da carne menos enjoativa (SILVA et al., 2014). Boa parte da literatura afirma que o principal entrave para consumo da carne suína pode estar atrelado à falta de esclarecimento sobre os benefícios que a carne suína pode trazer, e de investimentos em marketing que desmistifiquem os problemas relacionados às questões sanitárias e ao teor de gordura. A frequência de consumo pode ser aumentada, já que o preço não foi o fator limitante para o consumo.

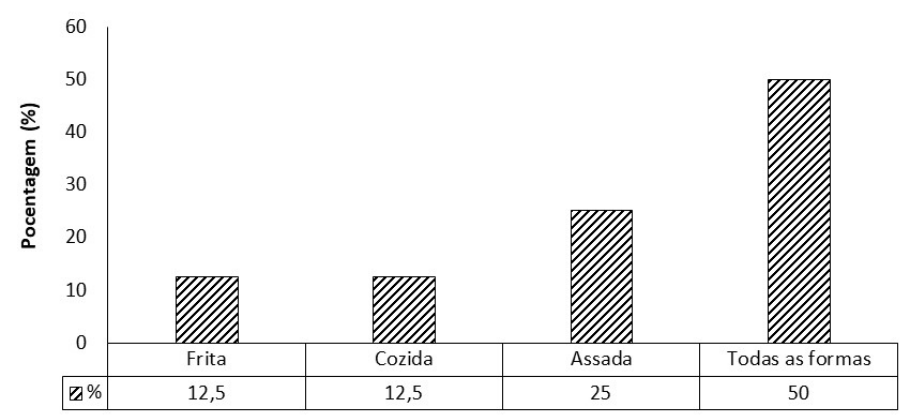

Figura 6: Preferência dos consumidores em Itapecuru Mirim pelo modo de preparo da carne suína 
Influência de fatores socioeconômicos e nutricionais no consumo de proteína animal em Itapecuru Mirim, Maranhão

ARAÚJO, R. A.; ALMEIDA, O. C.; SILVA, L. N. C. C.; MORAIS, S. F.; ALMEIDA, E. I. B.; ALMEIDA, R. M. V.; VERAS, D. A.; SOUSA, R. A.; CORREA, R. S.; RODRIGUES, E. S.; PACHECO, M. B.; BARROSO, V. B.

Em relação ao modo de preparo da carne de frango, teve como maior opção todas as formas de preparo (59\%), cozida (27\%), assada (10\%) e frita (4\%), conforme se observa na Figura 7. Esses resultados contrastam com o trabalho de Silva et al. (2015) que observaram resultados diferentes no município de Jataí no Estado do Goiás, onde 44,70 \% dos 150 entrevistados, afirmaram preferir consumir a carne de frango frita. Ambos os resultados mostram a tendência e preferência regional no tipo de preparo desta carne.

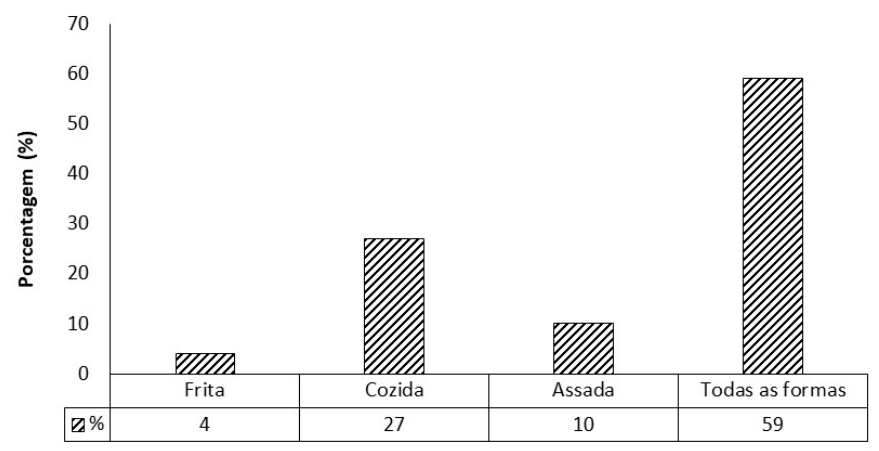

Figura 7: Preferência dos consumidores em Itapecuru Mirim pelo modo de preparo da carne de frango

Verificou-se a preferência dos consumidores pelo local de compra da carne bovina, onde teve como maior opção os frigoríficos (90\%), seguindo pelos supermercados $(10 \%)$, onde se observa que nenhum dos entrevistados adquirem a proteína bovina atrás de feiras livres (0\%), conforme se observa na figura 8.

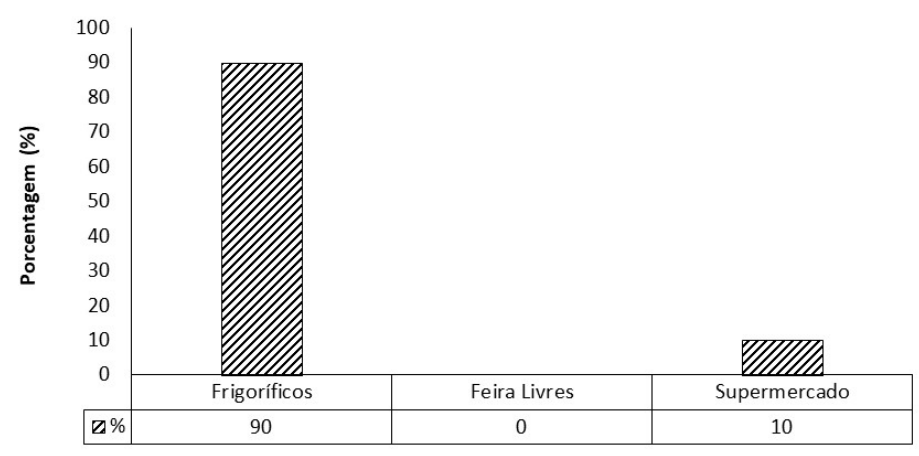

Figura 8: Preferência dos consumidores em Itapecuru Mirim pelo local de compra da carne bovina

Quanto ao local de compra da suína, $50 \%$ dos entrevistados escolheram os frigoríficos e $50 \%$ as feiras livres, onde nenhum dos entrevistados vão aos supermercados para fazer a compra carne suína (0\%), conforme se pode observar na figura 9.

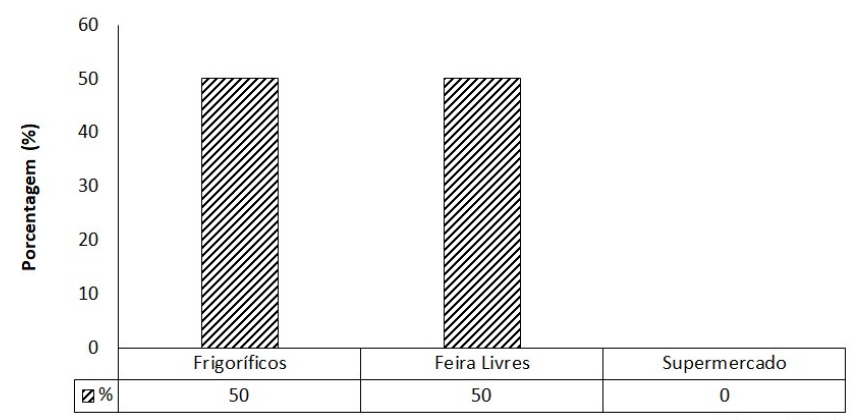

Figura 9: Preferência dos consumidores em Itapecuru Mirim pelo local de compra da carne suína 
Segundo a preferência dos consumidores entrevistados, quanto ao local de compra da carne de frango, tendo como maior preferência os frigoríficos (43\%), seguindo dos supermercados (47\%) e as feiras livres (10\%), conforme se pode observar na figura 10.

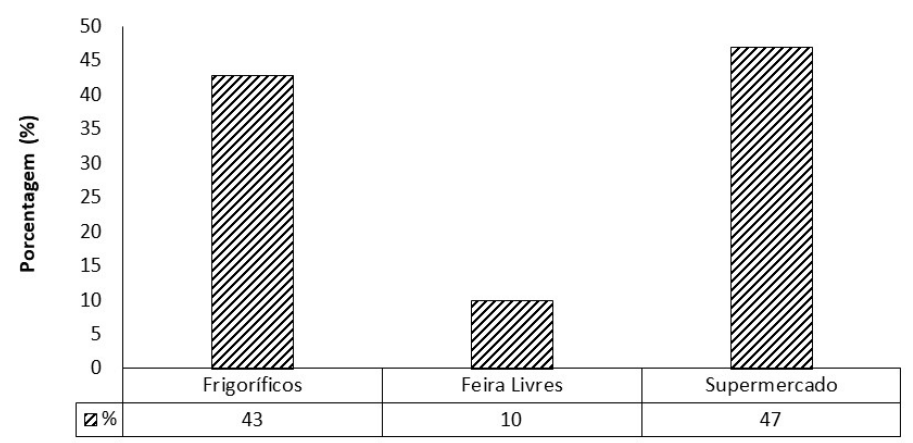

Figura 10: Preferência dos consumidores em Itapecuru Mirim pelo local de compra da carne de frango

Pesquisou-se o motivo da preferência dos consumidores no momento da compra da carne bovina, onde teve como maior opção a qualidade $(80 \%)$, seguindo da produção $(10 \%)$ e o preço $(10 \%)$, onde se observa que os consumidores não levam em consideração o preço (0\%) na hora da compra. Conforme se observa na Figura 11.

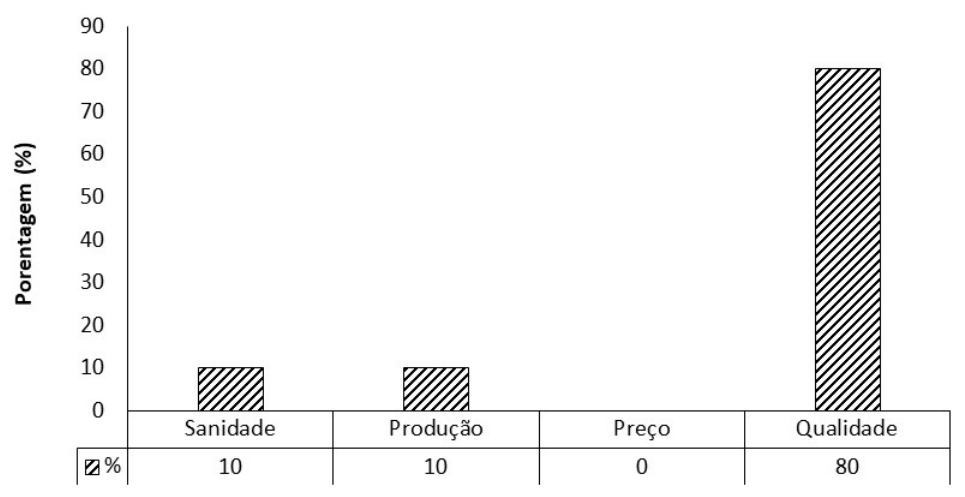

Figura 11: Motivo da preferência dos consumidores em Itapecuru Mirim no momento da compra da carne bovina

Quanto ao motivo dos consumidores no momento da compra da carne suína, teve como maior opção a qualidade $(75 \%)$, seguindo da produção $(12,5 \%)$, preço $(12,5 \%)$, sendo que os consumidores da carne suína não levam em consideração a sanidade (0\%) da proteína. (Figura 12). Esses dados são bem interessantes e controversos aos encontrados na literatura. Pois muitas das pesquisas mostram que os consumidores acham que a carne suína apresenta baixo valor nutritivo. Pois, embora a maioria dos consumidores acredite que a carne suína possua menor qualidade nutricional do que as carnes bovina e de frango, dados científicos mostram que a carne suína é rica em proteínas e fonte importante de vitaminas B1, B2, B6, B12 e A, possuindo ainda baixo valor energético, em torno de 147 kcal/100 g (Rodriguez-Amaya, 2002). Em comparação com a carne bovina, a carne suína apresenta maior teor de aminoácidos essenciais, como leucina, lisina e valina (Pimentel, 2007). Logo, os resultados mostram que os consumidores de Itapecuru-Mirim estão bem-informados acerca da qualidade nutricional da carne suína. 


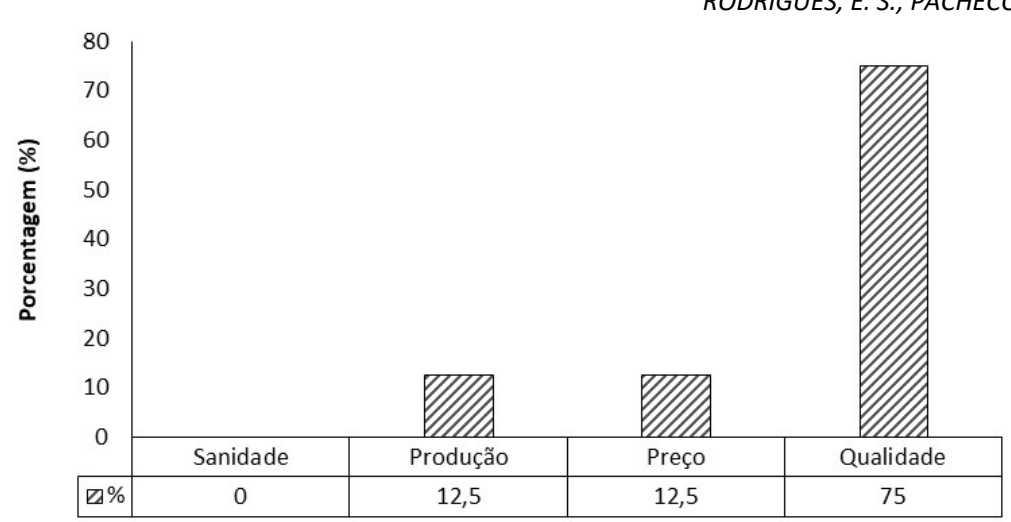

Figura 12: Motivo da preferência dos consumidores em Itapecuru Mirim no momento da compra da carne suína.

Quanto à preferência dos consumidores no momento da compra de frango, teve como maior opção a qualidade (75\%), seguindo o preço (16\%), a produção (5\%) e a sanidade $(4 \%)$. Conforme se observa na figura 13.

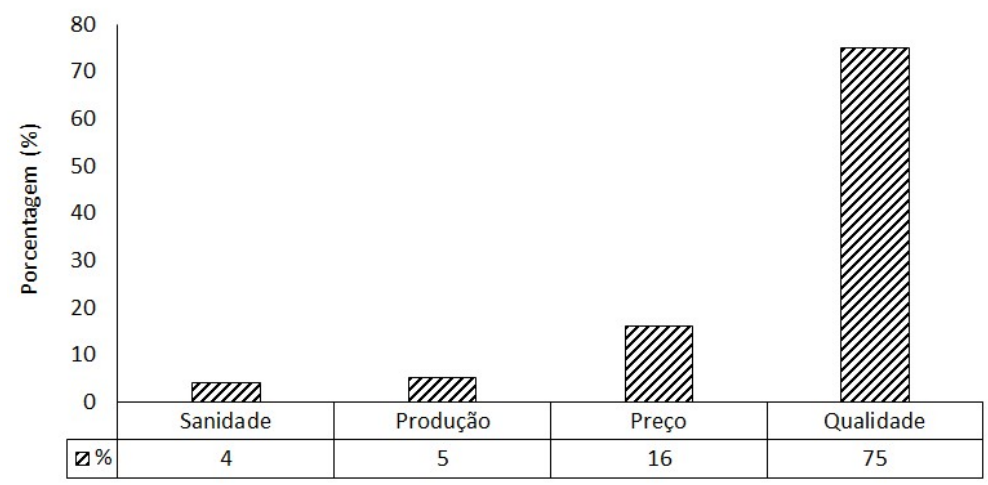

Figura 13: Motivo da preferência dos consumidores em Itapecuru Mirim no momento da compra da carne de frango.

Observou-se a porcentagem dos consumidores de Itapecuru Mirim que tem conhecimento sobre os sistemas de produção dos bovinos, suínos e frangos (A), onde $68 \%$ sabem e $32 \%$ não. Conforme observa-se na figura 14. Em seguida analisou se os entrevistados tem alguma preferência por marca (B) no momento da compra, onde 63\% responderam sim, e 37\% não. Conforme observa-se na figura 14.

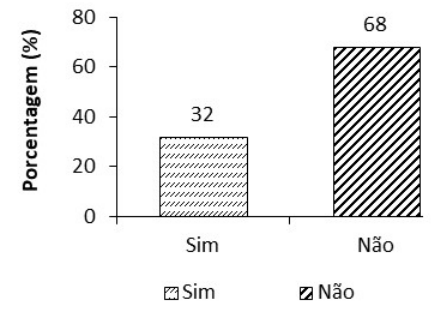

(A)

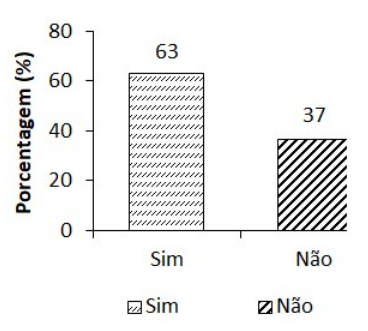

(B)

Figura 14: Porcentagem de consumidores de Itapecuru Mirim que tem conhecimento sobre os sistemas de produção dos bovinos, suínos e frangos (A) e preferência por marca de produto (B).

Analisou-se a porcentagem de consumidores que relacionam a produção animal com danos ao meio ambiente, onde teve como maior opção que em partes prejudica (36\%), seguindo dos entrevistados que não souberam responder (24\%), aqueles que responderam que prejudica (22\%) e que não prejudica (18\%). Conforme observa-se na Figura 15. 


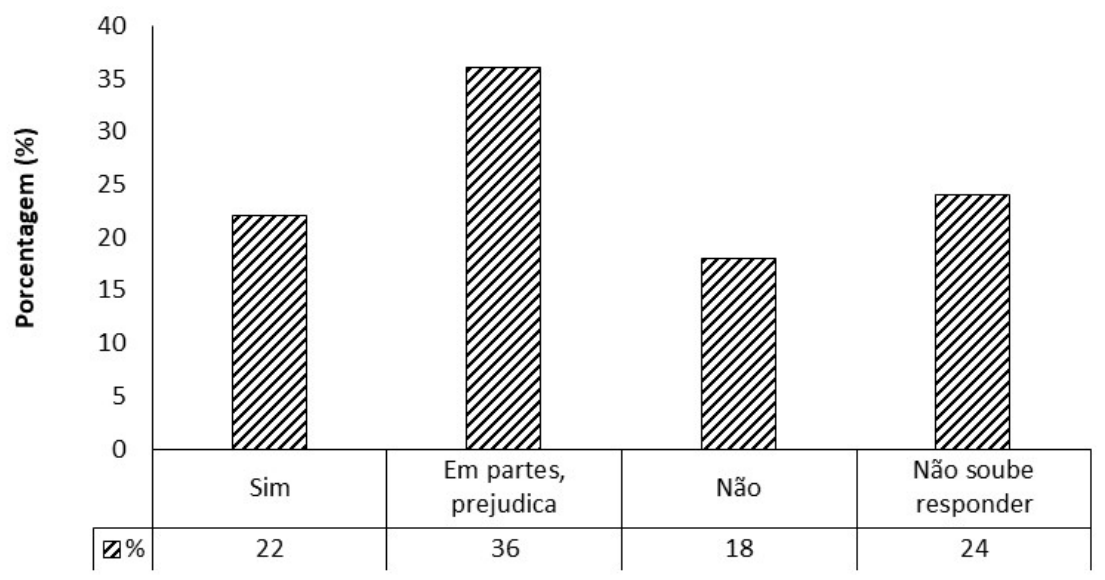

Figura 15: Porcentagem de consumidores de Itapecuru Mirim que relacionam a produção animal com danos ao meio ambiente.

Analisou-se a opinião dos entrevistados, em relação à qual espécies (Bovina, Suína, Frango) que traz maior impacto para o maranhão, onde teve-se como maior resultado o Bovino (64\%), em seguida o Suíno (25\%) e ficando em último lugar o Frango (13\%). Conforme observa-se na Figura 16.

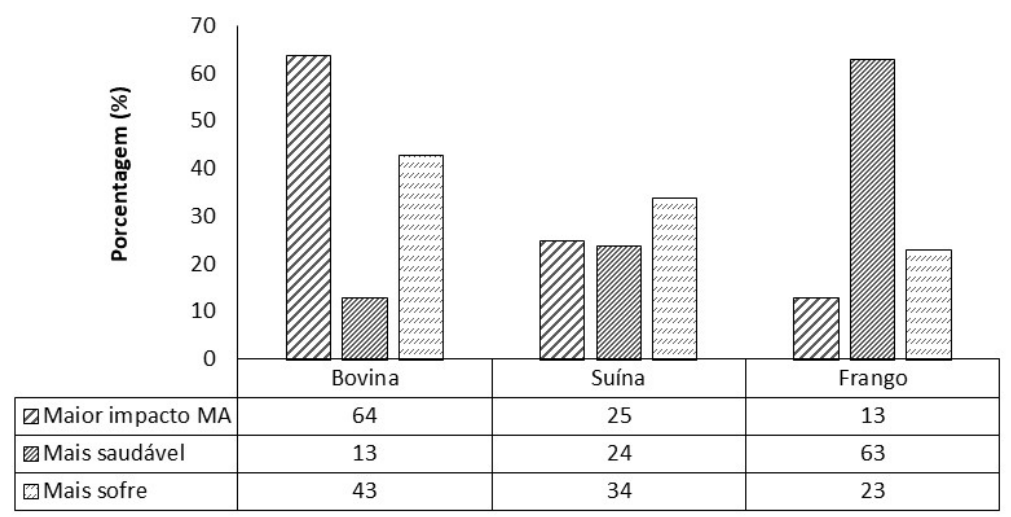

Figura 16: Porcentagem de consumidores de Itapecuru Mirim que relacionam a produção animal a cada um dos tipos de proteína animal a impactos no meio ambiente (MA), qual tipo consideram mais saudável e qual espécie mais sofre durante o processo de produção.

Logo depois foi-se questionado qual das proteínas animais (Bovino, Suíno, Frango) eles consideram mais saudáveis, ficando em primeiro lugar a carne de frango (63\%), em segundo lugar a carne Suína (24\%) e em terceiro a carne Bovina (13\%). Conforme observa-se na figura 17 . Foi-se questionado se os consumidores das proteínas animais já pensaram no bem estar dos animais antes de consumir qualquer tipo de carne, onde (74\%) disseram que Sim e (26\%) Não. Nordi et al. (2007), em pesquisa realizada em Curitiba, Paraná, com 600 indivíduos, perceberam a falta de conhecimento da população acerca dos procedimentos envolvidos no cenário da produção animal e relatam que uma sociedade mais informada poderia tomar decisões diferenciadas e gerar nichos de mercado. Por outro lado, Schaly et al. (2010), em questionário aplicado a 200 pessoas, em Rio Verde, Goiás, também constataram o desconhecimento dos consumidores sobre os métodos de criação de animais, ao verificarem que $49,01 \%$ não conhecem os métodos de criação animal e 50,90\% nunca tiveram contato com animais de produção. 


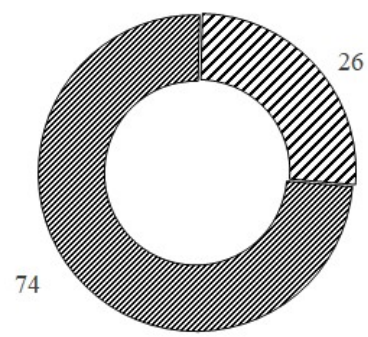

$\mathbb{Z} \operatorname{Sim}$

๒ Não

Figura 17: Porcentagem de consumidores de Itapecuru Mirim que já pensaram em bem-estar antes mesmo de consumir qualquer tipo de carne.

\section{CONCLUSÕES}

A carne de frango é mais consumida no município de Itapecuru Mirim. Além disso, os consumidores de produtos de proteína de origem animal têm pouco conhecimento acerca da origem da carne e não estão preocupados como ocorre a criação e abate de animais que originam os produtos que consomem.

\section{REFERÊNCIAS}

AGUIAIS, E. G.; FIGUEIREDO, R. S.. Correlação entre consumo de carne de frango e renda No Brasil (2002-2009). Qualia: a ciência em movimento, v.1, n.1, p.64-77, 2015.

BRAGAGNOLO, N.; RODRIGUEZ-AMAYA, D. B.. Teores de colesterol, lipídios totais e ácidos graxos em cortes de carne suína. Ciência e Tecnologia de Alimentos, v.22, n.1, p.98104, 2002. DOI:

https://doi.org/10.1590/S010120612002000100018

DEPARTMENT OF HEALTH. Dietary reference values for food, energy and nutrients for the United Kingdom. London: The Stationery Office, 1991.

FIGUEIREDO JÚNIOR, J. P.; GIVISIEZ, P. E.; SANTOS, E. G.; SANTANA, M. H. M.; OLIVEIRA, C. J. B.; SANTOS, T. S.; LIMA, D. F. F.. Caracterização do consumo e perfil do consumidor de frango da cidade de João Pessoa-PB. Revista Agropecuária Técnica, v.38, n.3, p.153-159, 2017. DOI: https://doi.org/10.25066/agrotec.v38i3.30015

GORDIN, M. H. O.. Estudo das cadeias produtivas do MS: avicultura. Cuiabá: UFMS, 2002.

LIMA JÚNIOR, D. M.; RANGEL, A. H. N.; URBANO, S. A.; MACIEL, M. V.; AMARO, L. P. A.. Alguns aspectos qualitativos da carne bovina: uma revisão. Acta Veterinaria Brasilica, v. 5, p.351-358, 2011. DOI: https://doi.org/10.21708/avb.2011.5.4.2368

NORDI, W. M.. Percepção e atitude em relação ao bem-estar de animais de produção em Curitiba, Paraná. In: CONGRESSO BRASILEIRO DE ZOOTECNIA, 18. Anais. Londrina, 2007.

RECK, A. B.; SCHULTZ, G.. Aplicação da metodologia multicritério de apoio à decisão no relacionamento interorganizacional na cadeia da avicultura de corte. Revista de Economia e Sociologia Rural, v.54, n.4, p.709-728, 2016. DOI: https://doi.org/10.1590/1234-56781806-94790540407

SANTOS FILHO, J. I.; BERTOL, T. M.. Efeitos da percepção dos atributos dos alimentos e das características dos consumidores sobre o consumo de carne suína. In: CONGRESSO DA SOCIEDADE BRASILEIRA DE ECONOMIA ADMINISTRAÇÃO E SOCIOLOGIA RURAL, 45. Anais. Brasília, 2007.

SCHALY, L. M.; OLIVEIRA, M. C.; SALVIANO P. A. P.; ABREU, J. M.. Percepção do consumidor sobre bem-estar de animais de produção em Rio Verde, GO. Pubvet, v.4, n.38, p.19821263, 2010.

SILVA, C. M.; DIAS, M.; LOPES, K. L. A. M.; JUNQUEIRA, O. M.; NASCIMENTO, V. A.. Perfil do consumidor de carne de frango do município de Jataí-GO. Enciclopédia Biosfera, v.11, n.21, p.1468-1478, 2015.

SILVA, M. R.; SANTOS, M. O.; PINHEIRO, M. S. M.. Perfil do consumo de carne suína nos municípios de Glória d'oeste e Porto Esperidião. Revista ACSA, v.10, n.2, p.35-41, 2014.

UNITED STATES DEPARTMENT OF AGRICULTURE. Dietary guidelines for americans, 2010.

VELHO, J. P.; BARCELLOS, J. O. J.; LENGLER, L.; ELIAS, S. A.; OLIVEIRA, T. E.. Disposição dos consumidores portoalegrenses à compra de carne bovina com certificação. Revista Brasileira de Zootecnia, v.38, p.399-404, 2009. DOI: https://doi.org/10.1590/S1516-35982009000200025

VERBEKE, W.; PÉREZ-CUETO, F. J. A.; BARCELLOS, M. D.; KRYSTALLIS, A.; GRUNERT, K. G.. European citizen and consumer attitudes and preferences regarding beef and pork. Meat Science, v.84, p.284-292, 2010. DOI: https://doi.org/10.1016/i.meatsci.2009.05.001

A CBPC - Companhia Brasileira de Produção Científica (CNPJ: 11.221.422/0001-03) detém os direitos materiais desta publicação. Os direitos referem-se à publicação do trabalho em qualquer parte do mundo, incluindo os direitos às renovações, expansões e disseminaç̃oses da contribuição, bem como outros direitos subsidiários. Todos os trabalhos publicados eletronicamente poderão posteriormente ser publicados em coletâneas impressas sob coordenação da Sustenere Publishing, da Companhia Brasileira de Produção Científica e seus parceiros autorizados. Os (as) autores (as) preservam os direitos autorais, mas não têm permissão para a publicação da contribuição em outro meio, impresso ou digital, em português ou em tradução. 